Letchner and Miss Christine Bramley for help with the analysis of the data.

REFERENCES

Angel, J. H., Fletcher, C. M., and Tinker, C. M. (1964). Awaiting publication.
Ashcroft, T. (1964). Brit. med. 7., 2, 1234.

Elmes, P. C., Dutton, A. A. C., and Fletcher, C. M. (1959). Lancet, 1, 1241.

Fletcher, C. M., Elmes, P. C., Fairbairn, A. S., and Wood, C. H. (1959). Brit. med. $7 ., 2,257$.

- and Tinker, C. M. (1961). Ibid., 1, 1491.

Miller, D. L. (1963). Amer. Rev. resp. Dis., 88, 473.

\title{
Rapid Stick Method for Determining Blood-glucose Concentration
}

\author{
VINCENT MARKS, ${ }^{*}$ M.A., B.M., M.R.C.P.ED. ; A. DAWSON, $†$ F.I.M.L.T.
}

Brit. med. F., 1965, 1, 293-294

Abnormalities of glucose metabolism are among the commonest encountered in clinical practice, and measurement of blood glucose is one of the commonest laboratory investigations. Though simple to perform, accurate measurement of the blood glucose requires both apparatus and specialized technical skill, neither of which is immediately available to the physician called urgently to see a patient in coma or to the general practitioner caring for an ambulant patient with brittle diabetes.

We describe here our experience with a new technique which requires neither special technical skill nor apparatus, and which provides a clinically useful approximation of the blood-glucose concentration within one and a half minutes.

\section{Methods and Material}

The method (Kohn, 1957) depends upon matching the colour produced when one drop of blood is added to a specially prepared enzyme-impregnated strip-Dextrostix-with the colour chart provided, corresponding with a range of blood-glucose values of between 40 and $250 \mathrm{mg}$. $/ 100 \mathrm{ml}$. (the latter now relabelled " over $200 \mathrm{mg}$. $/ 100 \mathrm{ml}$.).

Either capillary or venous blood preserved with iodoacetate (Marks and Lloyd, 1963) but not fluoride may be used. The Dextrostix is impregnated with blood, which after one minute is washed off under a stream of running tap-water for 5-10 seconds. The pale-grey to bright-blue colour revealed thereby is immediately compared with the colour chart on the bottle.

\section{Investigation Technique}

The results of blood-glucose analysis obtained by means of Dextrostix were compared with those obtained in the laboratory by means of a glucose-oxidase method (Marks and Lloyd, 1963). The Dextrostix results were recorded immediately they were made. A number of individuals, mostly laboratory technicians, but including doctors, took part in the investigation in

Blood-glucose Concentration Measured by Dextrostix. Results Obtained by Observer V.M. and by Diabetic Patients Chosen at Random from

\begin{tabular}{c|cc|c|c|c}
\hline \multirow{2}{*}{ No. } & \multirow{2}{*}{ Age and Sex } & \multicolumn{3}{|c}{ Glucose (mg./100 ml.) } \\
\cline { 3 - 6 } & & & Observer V.M. & Patient & AutoAnalyzer \\
\hline 1 & 14 & M & 200 & 200 & 239 \\
2 & 20 & F & 150 & 170 & 191 \\
3 & 77 & F & 220 & 250 & 390 \\
4 & 67 & M & 130 & 150 & 112 \\
5 & 67 & F & 130 & 250 & 136 \\
6 & 70 & M & 220 & 250 & 356 \\
7 & 57 & F & 140 & 130 & 106 \\
8 & 56 & F & 65 & 65 & 76 \\
9 & 30 & F & 170 & 150 & 170 \\
\hline
\end{tabular}

order more closely to simulate the conditions under which the technique is likely to be used. A small number of patients attending the diabetic clinic also took part (see Table).

Specimens of blood were obtained from a number of sources. Many of the patients were out-patients or were attending the diabetic clinic. Samples were taken on a number of occasions from in-patients in a psychiatric hospital. Two were receiving modified insulin therapy, on some occasions with, and on some occasions without, intravenous fructose. A patient with spontaneous hypoglycaemia was also studied.

A few samples of cerebrospinal fluid were examined by the same technique as for blood.

\section{Results}

The results of 356 individual determinations are shown in the Chart. Within the physiological range 40-200 mg./100 $\mathrm{ml}$. results obtained with Dextrostix differed by less than 20 mg. $/ 100 \mathrm{ml}$. from the true value in $73 \%$ of the cases. In the remaining $27 \%$ larger errors were present-these tended to occur more often with high than with low blood-glucose levels. The errors were not consistently in one direction; overestimation of the glucose content by Dextrostix occurred slightly more often than underestimation. The percentage of large errors by different observers was similar. Nevertheless important differences were noted between different observerssome tended consistently to overestimate, others to underestimate. In the majority of cases there was no difficulty in matching, but more importance was attached to similarity of shade than intensity of the colour. Hesitation increased the chance of error, and hasty decisions were more reliable than " considered" judgments.

At blood-glucose concentrations above $200 \mathrm{mg}$. $/ 100 \mathrm{ml}$. the results obtained with Dextrostix were less reliable than in the physiological range, and the blood-glucose concentration was consistently underestimated. Nevertheless, of 50 consecutive cases in which the blood-glucose concentration exceeded 200 mg. $/ 100 \mathrm{ml}$., in only 10 was the result with Dextrostix below this figure; and in none of these did the hyperglycaemia in fact exceed $250 \mathrm{mg} . / 100 \mathrm{ml}$. In the hypoglycaemic rangethat is, blood-glucose values below $40 \mathrm{mg}$. $/ 100 \mathrm{ml}$.-the results obtained with Dextrostix were found to be completely dependable. No case of hypoglycaemia was wrongly diagnosed.

The method was not found suitable for quantitating glucose in the cerebrospinal fluid.

* Consultant Pathologist, Department of Chemical Pathology, Epsom District Hospital, Epsom, Surrey.

+ Senior Technician, Department of Chemical Pathology, Epsom Districe Hospital, Epsom, Surrey. 


\section{Comment}

The precision and accuracy of Dextrostix are not such as to replace measurement of glucose in the blood by established laboratory procedure but do meet the need for an always available simple screening method and permit clear differentiation the blood glucose at the bedside. Since it is easy to use, Dextrostix may, in selected patients, replace the self-employed semi-quantitative urinalysis methods in common use for control of diabetes in out-patients.

The shelf-life of Dextrostix has not been determined, but is probably limited. This, together with the present high cost, is

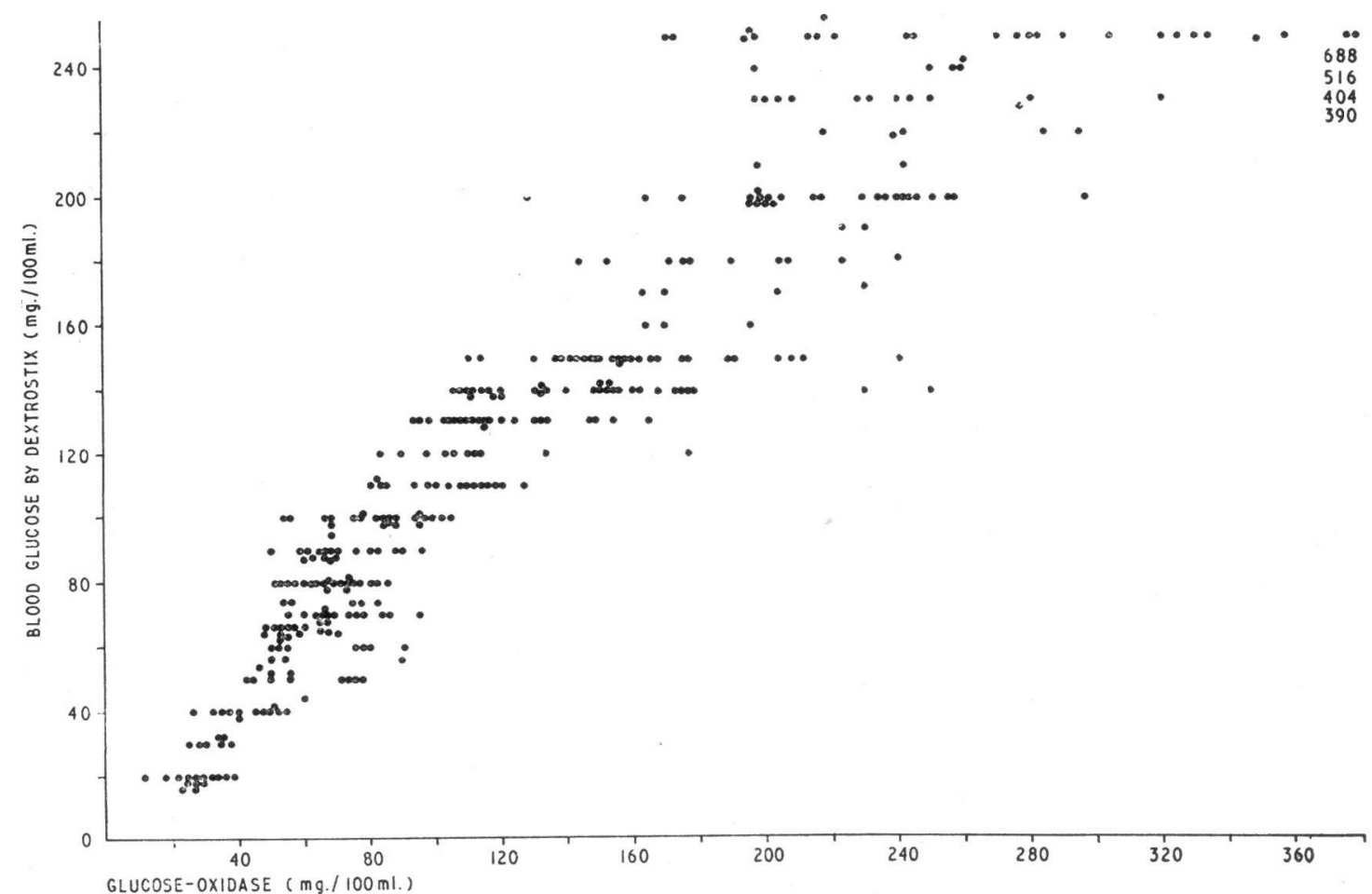

Comparison in 356 cases of blood-glucose results obtained with Dextrostix and with conventional laboratory glucoseoxidase methods.

between hypoglycaemia, normoglycaemia, and hyperglycaemia. It is noteworthy that the results for blood glucose obtained with Dextrostix correspond with those obtained by glucoseoxidase and not the older non-specific methods with which many clinicians are more familiar. The normal range for fasting blood glucose by glucose-oxidase is $50-90 \mathrm{mg} . / 100 \mathrm{ml}$., and symptoms of hypoglycaemia are rarely associated with blood-glucose values greater than $40 \mathrm{mg} . / 100 \mathrm{ml}$.

Because of its specificity Dextrostix is more reliable in the hypoglycaemic range than many widely used blood-sugar methods in common use. This is not so in the hyperglycaemic range, and cutting down the time of contact between Dextrostix and blood before washing does not improve quantitation at high blood-glucose levels.

The small amount of blood required makes the method suitable for serial blood-glucose estimations in infants with neonatal hypoglycaemia and other disorders of carbohydrate metabolism, and its portability convenient for measurement of likely to constitute a bar to its use except in cases of emergency or where turnover is rapid.

\section{Summary}

Experience with a new enzyme-impregnated strip for measuring the blood-glucose concentration is described. There is good agreement with conventional methods of blood-glucose measurement in the physiological and hypoglycaemic range. The technique is useful for recognizing, but not quantitating, blood-glucose concentration in the hyperglycaemic range.

We should like to thank Dr. G. Walker, of Ames Company, for supplying Dextrostix, and Dr. R. Bolton.

\section{REFERENCES}

Kohn, J. (1957). Lancet, 2, 119.

Marks, V., and Lloyd, K.' (1963). Proc. Ass. clin. Biochem., 2, 176. 